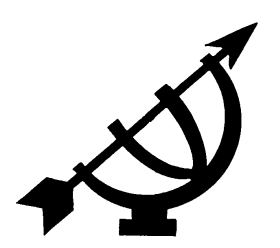

\title{
N.T. van der Merwe as denker
}

\author{
Johan Snyman \\ Departement Filosofie \\ Universiteit van Johannesburg \\ AUCKLANDPARK \\ E-pos: jsnyman@uj.ac.za
}

\section{Abstract \\ N.T. van der Merwe as thinker}

The philosophical legacy of N.T. van der Merwe is characterised as a profound concern for meaning, significance and nuance, especially as they are encountered and preserved in texts. This testifies to his inspiring pleasure in crafting rich texts himself, to his commendably thorough grasp of the history of thought and being filled with wonder and awe at the inexhaustible variety of the creation of God.

\section{Opsomming \\ N.T. van der Merwe as denker}

Die wysgerige nalatenskap van N.T. van der Merwe word getipeer as 'n diepgaande sorg om betekenis en nuanse, veral soos dit teëgekom word en vasgelê is in tekste. Dit getuig van sy inspirerende genot om self ryk tekste te maak, van sy bewonderenswaardige deeglike greep op die geskiedenis van denke en van sy verwondering oor die onuitputlike verskeidenheid van die skepping van God.

In Engels praat 'n mens van "a man of letters". In Afrikaans sal ek dit "'n mens vir tekste" noem. So 'n mens is iemand wat 'n teks met respek hanteer, nie net deur die wyse waarop sy hande die teks vashou en die boek versigtig oopbuig nie, maar iemand wat ook met groot respek praat oor wat ín die teks staan, want dit het die outeur van die teks baie moeite gekos om tot daardie uitspraak te kom, en hy of sy het talle redes moes oorweeg om dit juis en presies só te sê. So 'n mens praat met entoesiasme oor alles wat in 'n teks opgesluit lê: die besondere nuanse van die woord of frase in hierdie besondere teks; die onuitgesproke geskiedenis wat agter of onder 
hierdie frase lê; die verbande met ander diskoerse; die betekenis van die wyse waarop daar in die teks gekommunikeer word. So 'n mens kan sy verwondering oor die rykdom van 'n oënskynlik eenvoudige, miskien selfs terloopse stukkie gedrukte inligting nie vir homself hou nie. En so 'n mens put groot plesier daaruit om 'n teks uit 'n duisternis van besonderhede noukeurig, tydsaam, en met 'n register van stylkonvensies te weef, om op 'n onderbeklemtoonde, maar duidelik onderkenbare bewustelikheid die taal van die teks te plooi - soos dit die grasievolle, beheersende hand van die meester betaam. Dit is wat eerste by my opkom as ek aan die wysgerige nalatenskap van Theo van der Merwe dink.

Een van die eerste geskrifte van Theo waarmee ek kennis gemaak het, was sy onvergelyklike Grepe uit die kontemporêre wysbegeerte in die eeufeespublikasie van die Potchefstroomse Universiteit in 1969, Die Atoomeeu - in U Lig. Hierdie studie, met sy ryke inligting oor die filosofie van die eerste sewentig jaar van die twintigste eeu, sy fyn karakteriserings, sy ewe genuanseerde en oorwoë waardeskattings van filosofiese ontwikkelings en die versigtige, maar entoesiastiese perspektiewe op veral die toekomstige ontwikkeling van filosofie binne 'n Christelike gemeenskap, begin met die volgende sin:

'n Driesprong moet ek waag op die sandput van die huidige wysbegeerte (Van der Merwe, 1969b:76).

'n Treffende metafoor om mee te begin, maar iets is uit pas. Is dit dalk dat die filosoof - en die outeur van hierdie studie - 'n atleet is wat met inspanning spring en duik in 'n sandput op 'n atletiekbaan: 'n platonies geïnspireerde bedenking? Of is dit dalk omdat die huidige filosofie 'n sandput is waar 'n mens so ver as moontlik moet strek, waar 'n mens rekords moet oortref, waar 'n mens moet bewys dat jy ander deelnemers een voor is: 'n puriteinse agterdog teen die sug na individuele erkenning? Dan tref die sintaksis jou: dit is nie natuurlike taal nie, eerder gerek soos die vérspringatleet se treë, nominatief en akkusatief se plekke in die sin opsetlik omgeruil. Asof dit nie genoeg is nie, verskyn die eerste verwysing na 'n voetnoot voor die eerste punt agter die eerste sin in hierdie essay. Die voetnoot is 'n erkenning van die werk van kollegas en mentors, en niemand is te gering om genoem te word nie.

Die beeld van die filosoof as atleet is nie om dowe neute nie. Afgesien van die feit dat dit iets van Theo se eie liefde deur ervaring vir die atletiese agon te kenne gee, is twee ander - mekaar uitsluitende nuanses - ook hier op die spel. In sommige opsigte is 
die "huidige wysbegeerte" 'n kompetisie om die individueelste en kleinste moontlike logiese voordeel bo 'n ander argument, solank daar net 'n wenner is. Hierdie betekenis van die agonistiese aard van filosofie resoneer met die voorstelling wat in die studie gegee word van onder andere die Britse filosoof, G.E. Moore, se styl van die weerlegging van filosofiese idealisme. Kollegiaal/kameraadskaplik het Theo waardering vir wat Moore kan vermag, maar op die duur tref 'n ander nuanse van die filosofiese agon hom: die beeld van die vroeg-Christelike hermeet, "die atleet van Christus voortdurend [met] die oefenbaan [van die suiwering van gedagte en heiliging van die daaglikse in gemeenskap saam met ander vromes] onder die voete" - 'n formulering uit nog 'n studie wat in dieselfde jaar verskyn (Van der Merwe, 1969c:47). Hierdie laaste nuanse suggereer Theo se diepe verworteling in die Christelike klassieke die wêreld van die eerste Christelike intellektuele, die wêreld van Antonius en die ander woestynvaders, van Marius Victorinus, en Augustinus. 'n Deeglike en intieme kennis van die sfeer van die Christelike klassieke, en die bewerking daarvan in die Calvinistiese tradisie, kom telkens in Theo se werk na vore, wanneer hy homself - uit erkentlikheid, en nie ter wille van vertoon nie - genealogies plaas. Hy is altyd die dankbare gebruiker van voorgangers se werk, en die erkenning wat ander se werk deur sy eie werk kry, is telkens goeie getuienis van die arbeider van die teks, wat sy loon werd is.

Theo se geskrifte is buitengewoon ryk aan voetnote. Om so 'n teks te lees, verg baie aandag en toewyding om reg te laat geskied aan die groot sorg waarmee hierdie teks geskep is. Daar is iets esteties aan hierdie spel van voetnote en teks. Die voetnote is nie blote noukeurige dokumentasie van die oorspronge van die gedagtegang in die teks nie, dit is in die meeste gevalle boeiende suggesties van verdere kettings van idees en begrippe - selfs intellektuele reise deur landskappe waaruit die aangehaalde begrippe kom. 'n Mens kry as 't ware 'n gids in die voetnoot, wat jou nooi om saam met die outeur 'n fassinerende ontdekkingstog te onderneem, om agter te kom wat alles in die werklikheid steek. Een so 'n teks - 'n meesterstuk in eie reg - is Theo se Aspekte van 'n funksionele beskouing van verbeelding en van 'n tipologie van teorieë oor die verbeelding (Van der Merwe, 1969a). Wat nie alles in hierdie teks se voue ingewerk is nie, is eenvoudig verbysterend. Daar is deeglik verantwoorde vergelykende perspektiewe van die klassieke filoloog oor die etimologiese ontwikkeling van aenigma, provokatiewe uitsigte op die ontwikkeling van die gedagtegoed oor beeld, imago en imago Dei, 'n boeiende fenomenologie van verbeelding in sy ryke veelheid, en 'n kritiese gesprek met die grotes van die moderne 
tradisie (Hume, Locke, Kant, Ryle) oor die epistemologie van verbeelding, met - op onverwagse plekke - speelse aanhalings uit en verwysings na antikwariese rariteite, soos Rijmpies en raaisels, bijdrae tot die Suid-Afrikaanse volkskunde, 'n boek uit 1919 (voetnote 21 en 25). Die afwisselende spel van verwysings in hierdie teks skep 'n hele klomp inter- en metatekste wat betekenisse genereer en suggereer en wat as 't ware die teks vooruitloop, agterna herformuleer en dimensies van verstaan en toepassing suggereer. Al hierdie toespelings bring ' $n$ mens nie net onder die indruk van die kompleksiteit van die menslike verbeeldingsvermoë nie, maar laat 'n mens ook in jou pure menslikheid in verwondering oor die heerlikheid van verbeeldingryke nadenke.

Theo laat dikwels die sterk analitiese gedagtegang van die redenerende filosoof oorgaan in die aanmoedigende en bemoedigende woorde van die wyse mens. Ek dink hier aan een so 'n oomblik in die studie oor die verbeelding:

Geloofsverwagting, opstandingsgeloof, gelowige deurbreking van die op eerste gesig onmoontlike en oortroef van die ban van die skyn, oorspring van 'n muur met God (Ps. 18:30), realisering van die wonder - hoe sou dit sonder gelowige fantasie moontlik wees? (Van der Merwe, 1973:155).

Dit is sy omskrywing van die pistiese dimensie van verbeelding (nadat hy in terme van 'n fenomenologie van funksies van die verbeelding, na analogie van Dooyeweerd se teorie van wetskringe, onder andere die linguale, die historiese, die psigiese, die estetiese en die ekonomiese dimensies van die verbeelding aangesny het). As ek terugdink aan die tyd toe ek dit die eerste keer gelees het, in 1974, herleef ek weer die opwinding wat hierdie woorde in my wakker gemaak het. Gelowige fantasie - geloof wat die vermoë het om te verbeel! Dit skep 'n ruimte vir 'n kreatiewe toeëiening van en 'n deurdruk na iets wat nie onmiddellik gegee is nie, maar wat homself aankondig in die hart. Dit daag die baster vroom, maar futlose gepaai oor die beloop van die wêreld uit (toe die krake van die apartheidsbestel begin wys het en die wêreld die eerste skoorvoetende nawerkings van 'n Praagse Lente begin vermoed het) om werklik in navolging van Christus, met stoute skoene, 'n uitweg te soek en te bewandel. Ek was bevoorreg om te kon toesien hoe Theo se akademiese woorde ook sy lewenstyl was - 'n verbeeldingryke geloof het hom gedra, in 'n verwagting dat sy gespreksgenoot of die outeur met wie hy hom besig hou, altyd iets besonders en iets unieks het om te bied, altyd vol mededoë om die ander in staat te stel om haar of sy bydrae te lewer, immer gereed 
om die kleinste blyk van die geestelik kosbare ' $n$ veilige hawe te bied. In die gesprek en deurdink saam met Theo het so baie kwessies tuisgekom wat "der Welt abhanden gekommen [sind]", (om 'n frase van die Duitse digter, Heinrich Rückert, en wat op 'n roerende wyse deur Gustav Mahler getoonset is, te gebruik).

Maar terug by Theo se voetnootbelaaide tekste: daar is ook 'n ander dimensie aan Theo se rykdom aan inligting. Hy was 'n mens wat geseën is met 'n diepgaande historiese besef. As filosoofwetenskaplike was hy die kundigste eksponent in Suid-Afrika van die filosofiese historiografie van die Nederlandse filosoof, D.H. Th. Vollenhoven, en saam met Calvin Seerveld van die Institute of Christian Studies in Toronto, Kanada, miskien didakties die beste vertolkers in geskrifte van hierdie historiografie in die wêreld. In Theo se geskrifte is 'n mens bewus van 'n voortdurende getimmer en geskaaf aan ' $n$ historiografie van die filosofie. Daar is inderdaad 'n ongepubliseerde - ongeskrewe? - hoeveelheid kennis oor die geskiedenis van die filosofie wat wag op ontginning in Theo se nalatenskap, en in die filosofie wat voortgekom het uit die werk van Vollenhoven en sy studente. Theo verwys telkens na navorsing wat onderneem word en waarvan afhandeling en publikasie in die vooruitsig gestel word. Ons weet watter het nie werklikheid geword nie - watter het nie-teks gebly. Ons kan vir onsself, met 'n goedige of 'n meewarige glimlag sê dat daar by Theo dalk nog iets gespook het van die heroïese negentiende-eeuse strewe na omvattendheid en oorsigtelikheid - 'n strewe wat moeilik vrede gemaak het met die gedwonge fragmentarisering van twintigste-eeuse arbeidspraktyke. Of - en dit is vir my meer in ooreenstemming met Theo se persoonlikheid as twintigste-eeuse mens - ons kan ook sê dat dit 'n erkenning van die voorlopigheid van alle historiese interpretasie is. Elke terugsoek na die historiese verwikkeldheid begin onvermydelik by die jongste stoflaag en die jongste botsels, en ontdek dan haarwortels neffens die reeds bekende wortels, terug na 'n vertakking of 'n oorsprong. Hierdie besef van groei en verandering, as genadige en geheimenisvolle blyke van die geskapenheid van die wêreld deur 'n Skepper (want wie kan die gronde daarvoor ooit ten volle begryp?), het Theo altyd met ontsag vervul. Dit het hom gelei om versigtig, noulettend, die regte nuanse te gebruik om verslag te doen van wat hy in ander se werk bevind het. As voorbeeld dink ek hier aan sy oorwoë opweging van die standpunte van John Robinson, Paul van Buren en Harvey Cox in sy studie oor sekularisasie (Van der Merwe, 1969c), of die betekenis wat "sekulêre geskiedenis" vir die verstaan van Bybelse geskiedenis bied (Van der Merwe, 1971). Theo se probleem-historiese analises 
wil altyd reg laat geskied aan die volledig moontlikste spektrum van 'n denker se argumente - daarom word die haalbare hoeveelheid vesels van die gedagtelyn presies weergegee, sodat 'n mens 'n gunstige indruk het van die opsies wat moontlik is binne die bespreekte en geanaliseerde gesigspunt. Theo maak die aanknopingspunte vir die geïnteresseerde leser oop, en dan wys hy hoe die denker onder bespreking keuses maak, wat 'n mens laat wonder of dit die beste moontlike opsies is wat hy kon gevolg het. Die kritiese in-gesprek-tree met die ander standpunt dawer nie met 'n gesagvolle imprimatur nie, nog minder met 'n skelle veroordeling tot 'n reeds oorbekende en oorvol teerputs van dwaling.

Ek het die denker Theo van der Merwe gekarakteriseer as 'n mens vir tekste. Ek mag myself verskoon deur te sê dat hy in 'n sekere sin self hiervoor verantwoordelik was. Of as dit nie hy was nie, mag dit dan 'n geval wees van die wyse waarop legendes in die akademiese wêreld gevorm word. Want in Potchefstroom staan die naam van N.T. van der Merwe ook vir die outeur van dié meesterlikste verhandeling van alle Magisterverhandelings (Van der Merwe, 1958). Daar is baie waarheid in hierdie, somtyds humoristiese, oordrywing. Dit gaan nie bloot om die 533 outydse, groot foliobladsye $(220 \times 325 \mathrm{~mm})$ wat 'n lywige boek van $80 \mathrm{~mm}$ dik en amper $7 \mathrm{~kg}$ swaar maak nie. Dit gaan om die ongelooflike vakmanskap wat so 'n professioneel versorgde teks kon voortbring in 1958 met tikmasjien, wasvelle en afrolwerk, en wat die skrywer kennelik ook baie plesier verskaf het, as 'n mens ag gee op die volgehoue keurige taal en die subtiele spel van retoriese middele in die teks. Dit gaan ook veral om daardie vakmanskap en intellektuele spankrag, wat op die jeugdige ouderdom van 26 'n weergalose bestekopname van 'n sistematiese filosofie (veral na aanleiding van Herman Dooyeweerd, maar ook van H.G. Stoker, Vincent Hepp en andere) en 'n historiografie van die geskiedenis van denke oor logika, in die spore van D.H. Th. Vollenhoven kon lewer - 'n summa in die beste filosofiese sin van die woord.

Dit verwonder 'n mens dan ook nie dat Theo se laaste geskrif 'n teks is waarin teks as sodanig weer sentraal is: On the trail of John Calvin's philosophy of language: a few notes on his commentary on Genesis 10 and 11 (Van der Merwe, 2004). Teen hierdie tyd verbaas die aandag vir die lang, fyn historiese wortels van betekenisse nie meer nie; die verrassing oor wat die speurtog oplewer, is nog steeds - onmiskenbaar - daar. Calvyn word nie voorgehou as 'n onbetwisbare outoriteit nie, maar as 'n bedrewe, wyse en verantwoordelike smid van die woord. "I think it would be fair to say that Calvin used a comparative method to his advantage, 
highlighting God's grace in history," (Van der Merwe, 2004:124) laat hy 'n mens konkludeer nadat hy ons voorgegaan het in die naspeur van die maak van Calvyn se teks oor die teks van Genesis 11 (Van der Merwe, 2004:124). Calvyn is 'n maker van tekste, en die nate van hierdie tekste - hulle menslikheid, en daarom hulle begaafdheid - is iets wat nagevors kan word en wat die leser, ook van Calvyn se tekste, net kan verryk in die verstaan daarvan. Dít kan Theo weer nie nalaat nie; hy moet weer 'n verbeeldingryke inkyk in die wonder van woord en van woorde en van die Woord in hulle betrokkenheid op mekaar gee:

The Bible presents several marvellous beacons, which witness to the function of language, such as God creating the universe by the power of his Word, naming items of creation and conversing with humankind, even renaming persons and eventually confusing the builders of a mighty city; the 'grandparents' of humanity, naming, speaking and responding to God; or God's lingual commandments on durable tablets; a snake talking to Eve, and Bileam surprising us with a donkey talking lingual sense; a writing on the wall of a royal court; a choir of angels praising God; the seven last words of Jesus and the cross on Golgotha charging the divine Saviour of the world in the prominent languages used in Palestine at that time; a miraculous adaptation to a variety of vernacular languages, close-circuiting a translation crisis; letters from heaven to various churches, and much more (Van der Merwe, 2004:119).

'n Universiteit soos die Potchefstroomkampus van die NoordwesUniversiteit kan haarself as buitengewoon bevoorreg beskou om die kragte, talente en die gees van 'n Nicolaas Theodor van der Merwe tot haar beskikking te kon hê. Universiteite word geken en behoort altyd en uitsluitlik geken te word aan die werke van die groot geeste wat hulle gehuisves het. Daarom verleen die digkuns van Totius en T.T. Cloete, H.G. Stoker se Wysbegeerte van die Skeppingsidee, Gerrit Dekker se baanbrekersgeskiedenis van die Afrikaanse letterkunde, die werk van die historikus D.W. Kruger, van die klassikus Ferdinand Postma, van die wiskundige Dirk van Rooy, van die juriste L.J. du Plessis, H.L. Swanepoel en Johan van der Vijver (om enkeles te noem) groot aansien aan Potchefstroom. N.T. van der Merwe se Aspekte van 'n funksionele beskouing van verbeelding en van 'n tipologie van teorieë oor die verbeelding - as ek een teks durf uitsonder vir die gallery van akademiese werke wat 'n universiteit se bestaan regverdig - is een so 'n teks. Mag die Potchefstroomkampus van die Noordwes-Universiteit altyd 'n waardige trustee van tekste met sulke integriteit bly. 


\section{Geraadpleegde bronne:}

VAN DER MERWE, N.T. 1958. Op weg na 'n Christelike logika: 'n studie van enkele vraagstukke in die logika met besondere aandag aan D.H. Th. Vollenhoven se visie van 'n Christelike logika. (Ongepubliseerde M.A.verhandeling, $\mathrm{PU}$ vir $\mathrm{CHO}$.)

VAN DER MERWE, N.T. 1969a. Aspekte van 'n funksionele beskouing van verbeelding en van 'n tipologie van teorieë oor verbeelding. Philosophia Reformata, 34:147-178.

VAN DER MERWE, N.T. 1969b. Grepe uit die kontemporêre wysbegeerte. (In Die Atoomeeu - in U lig. Potchefstroom: Instituut vir die Bevordering van die Calvinisme. p. 76-112.)

VAN DER MERWE, N.T. 1969c. 'n Woning vir die jeug, anno Domini 1969 ? (Jeug en sekularisasie.) (In Korps Veritas Vincet. In die dae van jou jonkheid. Potchefstroom: Pro Rege. p. 45-77.)

VAN DER MERWE, N.T. 1971. Objektiwiteit, sekularisasie en geskiedenis. (In Truth and reality: philosophical perspectives on reality dedicated to Professor Dr. H.G. Stoker. Braamfontein: Boekhandel De Jong. p. 200221.)

VAN DER MERWE, N.T. 2004. On the trail of John Calvin's philosophy of language: a few notes on his commentary on Genesis 10 and 11. Acta Theologica Supplementum, 5:117-137.

\section{Kernbegrippe:}

filosofie, Christelik

teks

Van der Merwe, N.T.

Vollenhoven, D.H. Th.

\section{Key concepts:}

philosophy, Christian

text

Van der Merwe, N.T.

Vollenhoven, D.H. Th. 